\title{
Maternal inherited thrombophilia and pregnancy outcomes
}

\author{
DIANA IOANA VOICU ${ }^{1,3^{*}}$, OCTAVIAN MUNTEANU ${ }^{1,2^{*}}$, FLORENTINA GHERGHICEANU $^{4}$, \\ LUCIANA VALENTINA ARSENE ${ }^{1,3^{*}}$, ROXANA ELENA BOHILTEA ${ }^{1,5^{*}}$, \\ DELIA MARIA GRADINARU ${ }^{1}$ and MONICA MIHAELA CIRSTOIU ${ }^{1,5}$
}

\author{
${ }^{1}$ Department of Obstetrics and Gynecology, University Emergency Hospital of Bucharest, 050098 Bucharest; \\ ${ }^{2}$ Department of Anatomy, 'Carol Davila' University of Medicine and Pharmacy; ${ }^{3}$ Department of Obstetrics and Gynecology, \\ Doctoral School of 'Carol Davila' University of Medicine and Pharmacy; Departments of ${ }^{4}$ Marketing and Medical Technology \\ and ${ }^{5}$ Obstetrics and Gynecology, 'Carol Davila' University of Medicine and Pharmacy, 050474 Bucharest, Romania
}

Received March 10, 2020; Accepted April 9, 2020

DOI: $10.3892 / \mathrm{etm} .2020 .8747$

\begin{abstract}
Thrombophilia is a group of genetical disorders that cause blood to clot abnormally. Thrombophilia is linked to recurrent pregnancy loss, foetal growth restriction, late miscarriages, stillbirth and preeclampsia. Clinicians usually apply the term thrombophilia only to patients with atypical thrombosis. A successful outcome of pregnancy requires an efficient uteroplacental circulation. Since this system may be compromised by disorders associated with a prothrombotic state, it was postulated that maternal thrombophilia might be a risk factor for preeclampsia and intrauterine growth retardation. The study included 459 pregnant women with gestational ages ranging from 14 weeks to 28 weeks and the patients in the study were tested for hereditary thrombophilia. The type of thrombophilic mutation most common found was the MTHFR mutation (25.7\%), followed by the prothrombin gene mutation $(20.9 \%)$ and the Leiden factor V mutation (15.7\%). Also $15.03 \%$ patients had been diagnosed with preeclampsia and $6.75 \%$ of the pregnant women had IUGR fetuses.
\end{abstract}

\section{Introduction}

Thrombophilia is defined as a predisposition to thrombosis, being a pathology associated with increased tendency of venous thromboembolism. Thrombophilia contributes to more than half of thromboembolic events during pregnancy (1).

Thrombophilia is not a disease itself, but is an important risk factor for thrombosis. Thrombophilic defects can be

Correspondence to: Professor Roxana Elena Bohiltea, Department of Obstetrics and Gynecology, 'Carol Davila' University of Medicine and Pharmacy, 169 Splaiul Independenţei, District 5, 050474 Bucharest, Romania

E-mail: r.bohiltea@yahoo.com

*Contributed equally

Key words: thrombophilia, pregnancy, mutations, preeclampsia, intrauterine growth restriction accompanied by the following manifestations (2): Repeated miscarriages, intrauterine growth restriction, preeclampsia, HELLP syndrome and neonatal fulminant purple.

Fetal growth restriction may be linked to preeclampsia but is also associated with inherited thrombophilia. Multiple studies have reported an association between thrombophilia defects and adverse pregnancy outcomes, including both preeclampsia and intrauterine growth restriction. It is hypothesized a maternal predisposition to clotting would lead to thrombosis in the placental vasculature, thereby restricting oxygen and nutrient exchange, resulting in fetal growth restriction (3).

Preeclampsia plays an important role in maternal and fetal morbidity and mortality. Although the etiology of preeclampsia remains unknown, it has been suggested that abnormal placentation and endothelial cell dysfunction are key features in the pathogenesis of preeclampsia (4).

The most common maternal indication for early termination of pregnancy is preeclampsia, the most common fetal indication for early termination of pregnancy is intrauterine growth restriction accompanied by acute fetal distress (5).

Scientists are investigating thrombophilias at a molecular level, over the past 40 years many investigations have been conducted in relation to this condition. Multiple studies have been done in different types of populations to understand the inheritance patterns and risks for individuals diagnosed with an inherited thrombophilia (6). Familial thrombosis was initially considered an autosomal dominant disorder with varying penetrance. Nonetheless, recent studies suggest that congenital thrombophilia may be the result of the combination of two or more gene defects in a family (7).

American College of Obstetricians and Gynecologists (ACOG) recommends that screening for thrombophilia should be performed on patients with a personal history of venous thromboembolism that occurred during a transient risk factor (i.e., pregnancy, surgery, prolonged immobility); patients presenting with thrombosis at a young age ( $<40$ years), patients from families with a history of thrombosis ( $>2$ members), thrombosis at unusual site, more than 3 miscarriages, late miscarriage and foetal death (8).

Inherited thrombophilias include factor V Leiden mutation, prothrombin G20210A mutation (also referred to as factor II 
mutation), protein $\mathrm{C}$ deficiency, protein $\mathrm{S}$ deficiency, antithrombin deficiency and methylenetetrahydrofolate reductase mutations (9). Thrombophilia can lead to pregnancy complications, including miscarriage, IUGR and stillbirth $(10,11)$.

\section{Patients and methods}

A retrospective 6-month cohort study was conducted in University Emergency Hospital of Bucharest (Bucharest, Romania) between June-December 2018. We included in the study 459 pregnant women with gestational ages ranging from 14 weeks to 28 weeks. All the patients included in the study were tested for hereditary thrombophilia and laboratory samples, protein $\mathrm{C}$, protein $\mathrm{S}$, antithrombin III and homocysteine. Genetic analysis collected included mutations of factor V Leiden, gene MTHFR, mutation of factor XIII and prothrombin G20210A gene mutation.

This study was approved by the Ethics Committee of the University Emergency Hospital of Bucharest and informed consent was obtained from all the patients.

Statistical calculation of value. Statistical data collection and processing of data were performed in SPSS version 21. Depending on the typology of the data, coding, analysis of the data and the application of the statistical tests were performed. Also Cramer V (Cramér's phi) test and cluster analysis were performed. Cramér's V varies from 0 (corresponding to no association between the variables) to 1 (complete association) and can reach 1 only when each variable is completely determined by the other.

Based on the literature, the interpretation of Cramer $\mathrm{V}$ values is described in Table $\mathrm{I}$.

The objective of cluster analysis is to find similar groups of subjects, where 'similarity' between each pair of subjects means some global measure over the whole set of characteristics (Table I) (12).

\section{Results}

The presence of thrombophilic mutations are the result of laboratory analyzes and the normality interval recorded depends on the laboratory reagents used so we opted to investigate the actual values of protein $S$ and protein $C$ by cluster analysis. Thus, using cluster analysis, we classified thrombophilic mutation levels into 3 categories, deficiency, normal and excess.

The average age of patients included in the study was 33 years $( \pm 5.20)$, the average weight was $68 \mathrm{~kg}( \pm 12.42)$, the average height was $165 \mathrm{~cm}( \pm 10.20)$ and the average body mass index was $25.20( \pm 4.62)$.

The average value of protein $\mathrm{S}$ was $50.57 \%( \pm 13.68)$, with a variation between 20.1 and 111.8. According to the cluster analysis, the number of patients with protein $S$ deficiency was 68 , the number of patients with normal level of protein $\mathrm{S}$ was 230 , and the number of patients with protein $\mathrm{S}$ excess was 161 (Table II).

The average value of protein $\mathrm{C}$ was $114.37 \%( \pm 69.52)$, with a variation between 7.5 and 1078.0. According to the cluster analysis, the number of patients with protein $\mathrm{C}$ deficiency was 32 , the number of patients with the normal level of protein $\mathrm{C}$ was 380 , and the number of patients with protein $\mathrm{C}$ excess was 47 (Table III).
Table I. The interpretation of Cramer V values.

\begin{tabular}{ll}
\hline Value & \multicolumn{1}{c}{ Interpretation } \\
\hline 0 & No association \\
1 & Perfect association \\
$<0.10$ & Poor association \\
$0.10-0.30$ & Weak to moderate association \\
0.30 & Moderate association \\
$0.30-0.50$ & Moderate to strong association \\
0.50 & Strong association
\end{tabular}

Table II. Classification of the protein S level according to the cluster analysis.

\begin{tabular}{lcc}
\hline Category & Frequency & Percentage $(\%)$ \\
\hline Valid data & & \\
Deficit & 68 & 14.8 \\
Normal & 230 & 50.1 \\
Excess & 161 & 35.1 \\
Total & 459 & 100.0 \\
\hline
\end{tabular}

Table III. Classification of the protein $\mathrm{C}$ level according to the cluster analysis.

\begin{tabular}{lcc}
\hline Category & Frequency & Percentage $(\%)$ \\
\hline Valid data & & \\
Deficit & 32 & 7.0 \\
Normal & 380 & 82.8 \\
Excess & 47 & 10.2 \\
Total & 459 & 100.0 \\
\hline
\end{tabular}

In the study group, $15.03 \%$ patients had been diagnosed with preeclampsia and $6.75 \%$ of the fetuses had intrauterine growth restriction (Table IV).

Fetal growth restriction is a condition in which fetus is smaller than expected for gestational age. It is described as an estimated weight lower than the 10th percentile.

The type of thrombophilic mutation most common in the study group was the MTHFR mutation (25.7\%), followed by the prothrombin gene mutation $(20.9 \%)$ and the Leiden factor $\mathrm{V}$ mutation $(15.7 \%)$ (Table V).

Determination of the correlation and risk between high risk thrombophilia and IUGR. In this study only data with statistical significance $(\mathrm{P}<0.05)$ were used, and Chi-square test was employed to ascertain the association.

The results showed that the value of the Cramer V coefficient reveals an association of moderate to strong intensity between the presence of prothrombin mutation and the presence of intrauterine growth restriction (Cramer's $\mathrm{V}=0.33$, $\mathrm{P}<0.001)$. Patients who had prothrombin mutation had a 11.69 
Table IV. Distribution of obstetric pathology.

\begin{tabular}{lcc}
\hline Obstetric pathology & Frequency & Percentage (\%) \\
\hline No medical history & 359 & 78.21 \\
Preeclampsia & 69 & 15.03 \\
Intrauterine growth restriction & 31 & 6.75 \\
\hline
\end{tabular}

Table V. Thrombophilic mutations in this study group.

\begin{tabular}{lcc}
\hline Thrombophilic mutations & Frequency & Percentage (\%) \\
\hline Protein S deficiency & 68 & 14.8 \\
Protein C deficiency & 32 & 7.0 \\
Factor V Leiden & 72 & 15.7 \\
Prothrombin G20210A & 96 & 20.9 \\
MTHFR mutations & 118 & 25.7 \\
Hyperhomocysteinemia & 48 & 10.5 \\
Antithrombin deficiency & 47 & 10.2 \\
Factor XIII deficiency & 59 & 12.9 \\
\hline
\end{tabular}

higher risk of having a fetus with intrauterine growth restriction, compared with pregnant women who did not have this thrombophilic mutation (Table VI).

The results showed that the value of the Cramer V coefficient reveals a strong association between antithrombin deficiency and the presence of intrauterine growth restriction (Cramer's V=0.59, $\mathrm{P}<0.001$ ). Patients with antithrombin deficiency have a 60.37-fold increased risk of having intrauterine growth restriction compared to pregnant women without thrombophilic mutation (Table VII).

\section{Discussion}

Proteins $\mathrm{C}$ and $\mathrm{S}$ are two vitamin $\mathrm{K}$-dependent plasma proteins and are part of the natural anticoagulant system. Many pregnant women deficient in proteins $\mathrm{C}$ and $\mathrm{S}$ have been described and have an associated thrombotic tendency, but not all of them will experience thrombotic complications (13). In this study, we obtained mostly normal values of proteins $\mathrm{C}$ and $\mathrm{S}$. However, $14.8 \%$ (68 pregnant women) were diagnosed with protein $\mathrm{C}$ deficiency, and $7 \%$ (32 patients) were diagnosed with protein $\mathrm{S}$ deficiency.

Intrauterine growth restriction (IUGR) and preeclampsia are an important cause of fetal and neonatal morbidity and mortality. Some studies showed association between inherited thrombophilia and complications, such as interauterine fetal death, preeclampsia and placental abruption but association between IUGR and thrombophlia is still controversial (14).

Hypertensive disorders of pregnancy, including preeclam psia, consist of a spectrum of conditions which are associated with an important maternal and feta morbidity and mortality (15). The incidence in general population is estimated to be between 3 and $10 \%$ of all pregnancies $(16,17)$. In this study $15.03 \%$ of the patients were diagnosed with preeclampsia.
Table VI. Association between the presence of prothrombin mutation and the presence of intrauterine growth restriction.

\begin{tabular}{lccc}
\hline & & \multicolumn{2}{c}{$95 \%$ confidence level } \\
\cline { 3 - 4 } Items & Value & Minimum & Maximum \\
\hline $\begin{array}{l}\text { Odds ratio for IUGR } \\
\text { (yes/no) }\end{array}$ & 11.694 & 5.176 & 26.418 \\
Total patients & 459 & & \\
\hline
\end{tabular}

Table VII. Association between antithrombin deficiency and the presence of intrauterine growth restriction.

\begin{tabular}{lccc}
\hline & & \multicolumn{2}{c}{$95 \%$ confidence level } \\
\cline { 3 - 4 } Items & Value & Minimum & Maximum \\
\hline $\begin{array}{l}\text { Odds ratio for IUGR } \\
\text { (yes/no) }\end{array}$ & 60.373 & 23.561 & 154.696 \\
Total patients & 459 & & \\
\hline
\end{tabular}

The results from this study indicate that $15.03 \%$ patients had been diagnosed with preeclampsia and $6.75 \%$ of the fetuses had intrauterine growth restriction. The latest studies have suggested an important role of maternal thrombotic disorders in complications such as preeclampsia, intrauterine fetal death and IUGR.

In conclusion, we consider that thrombophilia is not a disease itself because a disease manifests when the symptoms of the disease begin, not when a diagnosis occurs.

Thrombophilia remains a pathological condition caused by a combination of risk factors. Thrombophilia refers to disorders which are associated with a persistent hypercoagulable state and a tendency towards thrombosis. Severe pregnancy complications such as preeclampsia and intrauterine growth retardation has been shown to be associated with thrombophilia.

Unfortunately, there is no curative treatment for thrombophilia, only prophylactic treatment with anticoagulants so pregnant women diagnosed with hereditary thrombophilia can be considered patients with high-risk pregnancies.

\section{Acknowledgements}

Not applicable.

\section{Funding}

No funding was received.

\section{Availability of data and materials}

The datasets used and analyzed during the current study are available from the corresponding author on reasonable request. 


\section{Authors' contributions}

DIV, LVA and DMG collected, analyzed and interpreted the patient data regarding pregnancy and thrombophilia. OM, FG, REB and MMC contributed substantially to the conception of the study and had a major role in writing the manuscript. All authors read and approved the final version of the manuscript.

\section{Ethics approval and consent to participate}

The study was approved by the Ethics Committee of the University Emergency Hospital of Bucharest (Bucharest, Romania) and informed consent was obtained from all the patients.

\section{Patient consent for publication}

Not applicable.

\section{Competing interests}

The authors declare that they have no competing interests.

\section{References}

1. Robertson L, Wu O, Langhorne P, Twaddle S, Clark P, Lowe GD, Walker ID, Greaves M, Brenkel I, Regan L, et al; Thrombosis: Risk and Economic Assessment of Thrombophilia Screening (TREATS) Study: Thrombophilia in pregnancy: A systematic review. Br J Haematol 132: 171-196, 2006.

2. Egeberg O: Inherited antithrombin deficiency causing thrombophilia. Thromb Diath Haemorrh 13: 516-530, 1965.

3. Roberts JM and Cooper DW: Pathogenesis and genetics of pre-eclampsia. Lancet 357: 53-56, 2001.

4. Polin RA, Fox WW and Abman SH: Fetal and Neonatal Physiology: Expert Consult-Online and Print. Elsevier Health Sciences, Philadelphia, PA, 2011.

5. Grandone E, Margaglione M, Colaizzo D, Pavone G, Paladini D, Martinelli P and Di Minno G: Lower birth-weight in neonates of mothers carrying factor V G1691A and factor II A(20210) mutations. Haematologica 87: 177-181, 2002.
6. Kupferminc MJ, Many A, Bar-Am A, Lessing JB and AscherLandsberg J: Mid-trimester severe intrauterine growth restriction is associated with a high prevalence of thrombophilia. BJOG 109: 1373-1376, 2002.

7. Koeleman BP, Reitsma PH and Bertina RM: Familial thrombophilia: A complex genetic disorder. Semin Hematol 34: 256-264, 1997.

8. Lockwood C, Wendel G; Committee on Practice BulletinsObstetrics: Practice bulletin no. 124: Inherited thrombophilias in pregnancy. Obstet Gynecol 118: 730-740, 2011.

9. James AH, Tapson VF and Goldhaber SZ: Thrombosis during pregnancy and the postpartum period. Am J Obstet Gynecol 193: 216-219, 2005.

10. Bates SM, Greer IA, Middeldorp S, Veenstra DL, Prabulos AM and Vandvik PO: VTE, thrombophilia, antithrombotic therapy, and pregnancy: Antithrombotic therapy and prevention of thrombosis, 9th ed: American college of chest physicians evidence-based clinical practice guidelines. Chest 141 (Suppl 2): e691S-e736S, 2012.

11. Marik PE and Plante LA: Venous thromboembolic disease and pregnancy. N Engl J Med 359: 2025-2033, 2008.

12. Kim HY: Statistical notes for clinical researchers: Chi-squared test and Fisher's exact test. Restor Dent Endod 42: 152-155, 2017.

13. Vossbeck S, de Camargo OK, Grab D, Bode H and Pohlandt F: Neonatal and neurodevelopmental outcome in infants born before 30 weeks of gestation with absent or reversed end-diastolic flow velocities in the umbilical artery. Eur J Pediatr 160: 128-134, 2001.

14. Said JM, Higgins JR, Moses EK, Walker SP, Monagle PT and Brennecke SP: Inherited thrombophilias and adverse pregnancy outcomes: A case-control study in an Australian population. Acta Obstet Gynecol Scand 91: 250-255, 2012.

15. Said JM, Higgins JR, Moses EK, Walker SP, Borg AJ, Monagle PT and Brennecke SP: Inherited thrombophilia polymorphisms and pregnancy outcomes in nulliparous women. Obstet Gynecol 115: 5-13, 2010.

16. Rodger MA, Betancourt MT, Clark P, Lindqvist PG, DizonTownson D, Said J, Seligsohn U, Carrier M, Salomon O and Greer IA: The association of factor V Leiden and prothrombin gene mutation and placenta-mediated pregnancy complications: A systematic review and meta-analysis of prospective cohort studies. PLoS Med 7: e1000292, 2010.

17. Wallis AB, Saftlas AF, Hsia J and Atrash HK: Secular trends in the rates of preeclampsia, eclampsia, and gestational hypertension, United States, 1987-2004. Am J Hypertens 21: 521-526, 2008. 